\title{
Removal of Tartrazine Yellow Dye From Aqueous Solution using Groundnut Shell as Biomass: Kinetic Approach
}

\author{
A.K. Asiagwu ${ }^{1}$, O.O. Emoyan ${ }^{1}$ and C.K. Ojebah ${ }^{2}$ \\ ${ }^{1}$ Department of Chemistry, Delta State University, Abraka, Nigeria. \\ ${ }^{2}$ Department of Science laboratory Technology, Delta State Polytechnic, Ozoro, Nigeria.
}

\begin{abstract}
The adsorption of tartrazineyellow dye using groundnut shell (Arachis Hypogea) as the biomass was investigated. The dye used in this study was a commercial (synthetic) dye. The dye solution was prepared by dissolving $10 \mathrm{mg}$ of the dye in about $1000 \mathrm{~cm}^{3}$ of distilled water. The various experimental parameters studied showed that the amount of dye adsorbed decreased from $0.213 \mathrm{mg} / \mathrm{g}-0.200 \mathrm{mg} / \mathrm{g}$ as the adsorbent dosage was increased from 2-6g. In a similar manner, the amount of dye adsorbed increased from0. $0.209 \mathrm{mg} / \mathrm{g} 213 \mathrm{mg} / \mathrm{g}$ - with increase in contact time from $20-100$ minutes. Also when the operating temperature wasincreased from $30^{\circ} \mathrm{C}$ to $70^{\circ} \mathrm{C}$, the amount of dye adsorbed increased from $0.202 \mathrm{mg} / \mathrm{g}-0.212 \mathrm{mg} / \mathrm{g}$ The adsorption capacity increased from $0.210 \mathrm{mg} / \mathrm{g}-1.213 \mathrm{mg} / \mathrm{g}$ with anincrease in concentration of dye from $10-50 \mathrm{mg} / \mathrm{g}$. And as the $\mathrm{pH}$ increases from $2.0-10.0$ the amount of dye decreased from $0.219 \mathrm{mg} / \mathrm{g}-0.205 \mathrm{mg} / \mathrm{g}$. While examining the bio-sorptionefficiency, Langmuir and Freundlich models were used. Thecoefficient of determination $\left(R^{2}\right)$ for both isotherms were 0.9988 and 0.9982 respectively which shows a monolayer surface process. Pseudo-first order kinetics and Pseudo-second order kinetics were used to analyze the experimental data in which the regression coefficient were observed to be 0.9072 and 1 respectively. Thermodynamic quantities like free energy $(\Delta \mathbf{G})$, enthalpy $(\Delta \mathbf{H})$ and entropy $(\Delta S)$ of the system were also evaluated and it was observed that the adsorption process was endothermic in nature, spontaneous, feasible and a reversible isothermal process.
\end{abstract}

Key words: Biomass. Groundnut shell, Tartrazine yellow dye, Adsorption kinetics, Thermodynamics studies

\section{INTRODUCTION}

Advancement in scientific research has brought about increase in industrialization and thus increase in anthropogenic sources of pollutants in our ecosystem (Asiagwu et al., 2013). The production of dyes and pigments by industries and many other establishments that utilize coloured substances are increasing globally (Graget al., 2004). The pigment and dyes are synthetic or naturally coloured substances used to modify the colour of materials or substances. The discharge of the dyes into the ecosystem is one of the sources of aesthetic pollution and eutrophication in surface water. (Mohamed, 2004) Consequently, water pollution is becoming a topic of serious concern. The most dangerous type of water pollution is the dyes and toxic metal ions present in industrial effluents and are often discharged to the aquatic body.
(Asiagwu 2013). However, the release of these wastes into natural water bodies is undesirable because it reduces the quality of natural water bodies hence, the ability to devastate the health of its consumers owing to its persistence and nonbiodegradability properties. Also, small quality of these coloured substances in effluent water are highly observable thus, the removal of colour from effluents containing various kinds of dyes becomes paramount (Asiagwu 2013).

Hence, this study investigates the use of groundnut (Arachis hypogea) shell biomass in the adsorption (removal) of Azo dyes (tatrazine yellow) from aqueous solutions by investigating the influence of dye adsorption over certain variables and applying the absorption kinetics to evaluate the efficiency of the process.

\section{MATERIALS AND METHODS}

Sample Collection and Preparation of Adsorbent Groundnuts (Arachis Hypogea) was bought from Abraka market in Ethiope East Local Government Area of Delta State, Nigeria. The seeds were removed and the shell was sun dried for some days. The dried samples were crushed with mortal and sieved using a $150 \mathrm{~mm}$ sieve. The sieved adsorbent was stored in a plastic container for analysis.

Preparation of Tartrazine Yellow Dye Solution

The dye (Tartrazine yellow) used in this work was obtained from a commercial market without further purification. The dye stock solution was prepared by dissolving $10 \mathrm{mg}$ of the dye in 1 litre of distilled water (1:100).

\section{SORPTION STUDIES}

Effect of Contact Time on the Sorption of Tatrazine Yellow in Solution

The adsorbent (Groundnuts shell) of about $2 \mathrm{~g}$ was weighed into five distinct conical flasks. The concentration of $10 \mathrm{mg} / \mathrm{L}$ of the Tartrazine dye was prepared using distilled water. $50 \mathrm{ml}$ of the dye solution was thereafter poured into the flasks. The five conical flasks were then tagged for the time interval of 20,40,60, 80 and 100 minutes as described by (Sumanjit et al., 2007). The flasks were then covered and agitated at the separate time interval. Towards the end of each time intervals, the suspensions were filtered via the Whatman No. 1 filtered paper and centrifuged using a centifuged. The concentration of the dye was measured with the aid of Unican UV spectrophotometer. (Sumanjit et al., 2007) 
Effect of the Adsorbent Dosage on Adsorption of Tartrazine Yellow in Solution

The experiment on the influence of adsorbent dosage on the removal of tartrazine dye ion by the groundnut shells (adsorbent) was conducted according to the method described by Sumanjit et al., (2007). 6,5,4,3 and $2 \mathrm{~g}$ of the groundnut shell were weighed into five distinct conical flaks. $50 \mathrm{ml}$ of the Tartrazine dye solution was poured into the five conical flasks. The five flasks were then labeled for dosage differences as noted above. The five flasks were then tightly covered and agitated for 20mins and after which the suspensions were filtered via Whatman No. 1 filter paper and centrifuged. The dye ion concentrations were measured using a U-V spectrophotometer. Sumanjit et al., 2007)

Studies on the Effect of Temperature on Adsorption of Tartrazine Dye in Solution

This study was conducted in line with the method as described by (Sumanjit, et al., 2007). The adsorbent of about $0.002 \mathrm{~g}$ was weighed into five separate conical flasks and $10 \mathrm{mg} / \mathrm{L}$ of the dye solution were measured in each of the five flasks. The flasks were labeled for temperature difference of 70,60, 50, 40 and 30C. The five flasks were then tightly covered and heated at their appropriate temperature with the means of a thermostatic water bath at 20mins for each. Towards the end of the experiment each of the flasks were brought out and agitated for about 5 minutes. Then the accompanying suspensions were filtered using Whatman No. 1 filtered paper and centrifuged. The dye ion concentration were measured Unican using U-V spectrophotometer. (Sumanjit, et al., 2007)

Investigation on the Effect of Dye ion Concentration on Adsorption

This was carried out following the method described by Sumanjit et al., (2007). Standard dye solutions of 50, 40, 30, 20 and $10 \mathrm{mg} / \mathrm{L}$ were prepared. $50 \mathrm{ml}$ of each of the solution were added to accurately weighed $2 \pm 0.01 \mathrm{~g}$ adsorbent in the five separate conical flasks and then agitated for 20 minutes. Towards the end of the time, the suspensions were filtered by the meansWhatman No. 1 filter paper and centrifuged. The dye ion concentration was estimated Unican using U-V spectrophotometer.

The Effect $\mathrm{pH}$ on Adsorption of Tartrazine Dye in Solution The experiment on $\mathrm{pH}$ adsorption was carried out based on the previous works of Sumanjit et al., (2007). Modified adsorbent (Groundnut shell) $(2 \pm 0.001 \mathrm{~g})$ was weighed into five separate flasks. $10 \mathrm{ml}$ of the dye solution was measured and added into each of the five different flasks. The PA solution was then adjusted to $\mathrm{pH} 2.0,4.0,6.0,8.0,10.0$ by adding a solution of $\mathrm{HCl}$ or $\mathrm{NaOH}$ and the $\mathrm{pH}$ reading were confirmed by the use of 3 in one $\mathrm{pH}$ meter as described by Sumanjit, et al., 2007. The conical flasks were tightly covered and agitated for 20 minutes. Towards the end, the suspensions were filtered via the Whatman filter paper and centrifuged with a centifugeed. The dye ion concentrations were measured via the Unican UV spectrophotometer.

\section{DATA EVALUATION}

The amounts of dye removal by the adsorbent during the series of the batch experiments were determined using amass equation as described by Sumanjit et al., 2007and Asiagwu et al., 2012, expressed below

qe $=(\mathrm{Co}-\mathrm{Ce}) \underline{V}$

\section{$M$}

Where:

$\mathrm{qe}=$ dye concentration on the biomass $(\mathrm{mg} / \mathrm{g})$ at equilibrium. $\mathrm{Ce}=$ dye concentration in solution $(\mathrm{mg} / \mathrm{L})$ at equilibrium.

$\mathrm{Co}=$ Initial dye concentration in solution $(\mathrm{mg} / \mathrm{L})$

$\mathrm{V}=$ volume of dye solution used $(\mathrm{ml})$

$\mathrm{M}=$ mass of adsorbent used $(\mathrm{g})$

\section{Kinetic Treatment of Experimental Data}

In order to fully evaluate the adsorption process, the equation of pseudo-first order and pseudo-second order mechanisms were applied as described by (Ho et al., 1995). The linear form of pseudo-first order model is stated below: $\ln (\mathrm{qe}-\mathrm{qt})=\operatorname{lnqe}-\mathrm{Kt}$ (Ho et al., 1995)

Where:

$\mathrm{qe}=$ mass of dye adsorbed at equilibrium $(\mathrm{mg} / \mathrm{g})$

$\mathrm{Qt}=$ mass of dye adsorbed at time $\mathrm{t}(\mathrm{mg} / \mathrm{g})$

$\mathrm{K}=$ equilibrium constant

The linear plot of In(qe-qt) versus t confirms the model.

The linear form of pseudo-second-order model which has been described previously is given below as:

$$
\frac{\mathrm{t}}{\mathrm{q}_{\mathrm{t}}}=\frac{\mathbf{1}}{\mathrm{h} \mathbf{0}}+\frac{\mathrm{t}}{\mathrm{q}_{\mathrm{e}}} \quad \text { (Ho et al., 1995) }
$$

Where:

$\mathrm{qt}=$ amount of dye ions on the adsorbent surface $(\mathrm{mg} / \mathrm{g})$ at anytime $\mathrm{t}$.

$\mathrm{qe}=$ the amount of dye ions adsorbed at equilibrium $(\mathrm{mg} / \mathrm{g})$

ho $=$ the initial adsorption capacity $(\mathrm{mg} / \mathrm{g} \mathrm{mm})$

The initial adsorption rate, ho is defined as:

ho $=\mathrm{k}_{2} \mathrm{qe}^{2}$

(Ho et al., 1995)

Where $\mathrm{K}_{2}$ is the pseudo-second order rate constant $(\mathrm{g} / \mathrm{mg}$ $\mathrm{mm}$ ) for the plot of $\frac{\mathbf{t}}{\mathbf{q}_{\mathbf{t}}} \mathbf{V s} \mathbf{t}$.

\section{RESULTS AND DISCUSSION}

Variation of Contact Time on the Adsorption of Tartrazine Dye in Solution

The influence of stay time for the sorption of the Tartrazine dye was studies between the intervals of 20-100 minutes.

The amount of dye ions reduced from $0.213 \mathrm{mg} / \mathrm{g}$ to $0.209 \mathrm{mg} / \mathrm{g}$ respectively.Figure 1 as shown below indicates that the amount of dye removed decreased with increase in time, together with the percentage of dye removed in which minimum percent $(83.6 \%)$ was obtained at 100 minutes.

This could be linked to the fact that as dye solution adsorbent system is being agitated at longer time, more of the molecules or atom of the tartrazine dye tend to accumulate on the surface of the adsorbate until equilibrium is reached. (Sumanjit, et al., 2007 Asiagwu, et al., 2012,) 


\section{$\%$ of dye removed vs time}

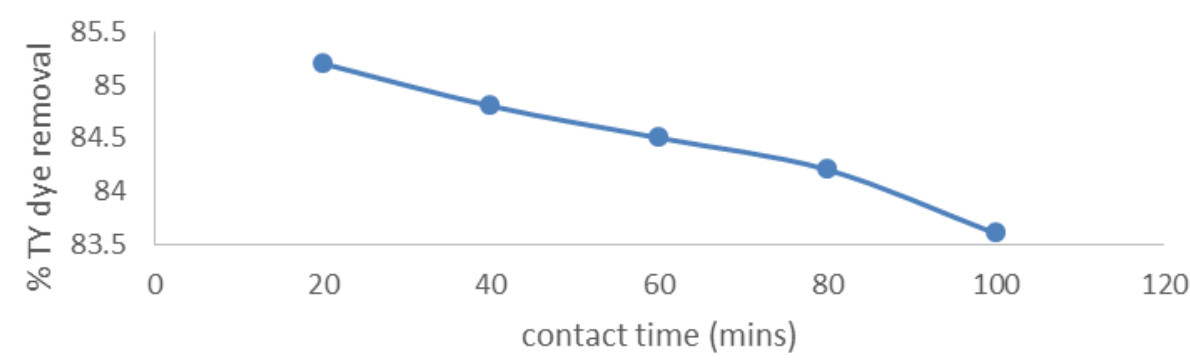

Fig. 1: Variation of contact time on the adsorption of Tartrazine dyes by groundnut shell adsorbent

Effect of adsorbent dosage on the Sorption of Tartrazine Yellow Dye in Solution

The effect of the amount adsorbent (groundnut shell) on the removal of tartrazine dye was studied in which the amount of adsorption was varied from $2 \mathrm{~g}$ to $6 \mathrm{~g}$.
Figure 2 shows that the effect of adsorbent dosage on dye removal decreased from $0.213 \mathrm{mg} / \mathrm{g}$ to $0.200 \mathrm{mg} / \mathrm{g}$ as the adsorbent dosage was increased from $2 \mathrm{~g}$ to $6 \mathrm{~g}$.

It was also observed that maximum percentage $(85.2 \%)$ of dye adsorbed was obtained from adsorbent dosage of $2 \mathrm{~g}$ and shown in figure 2 below.

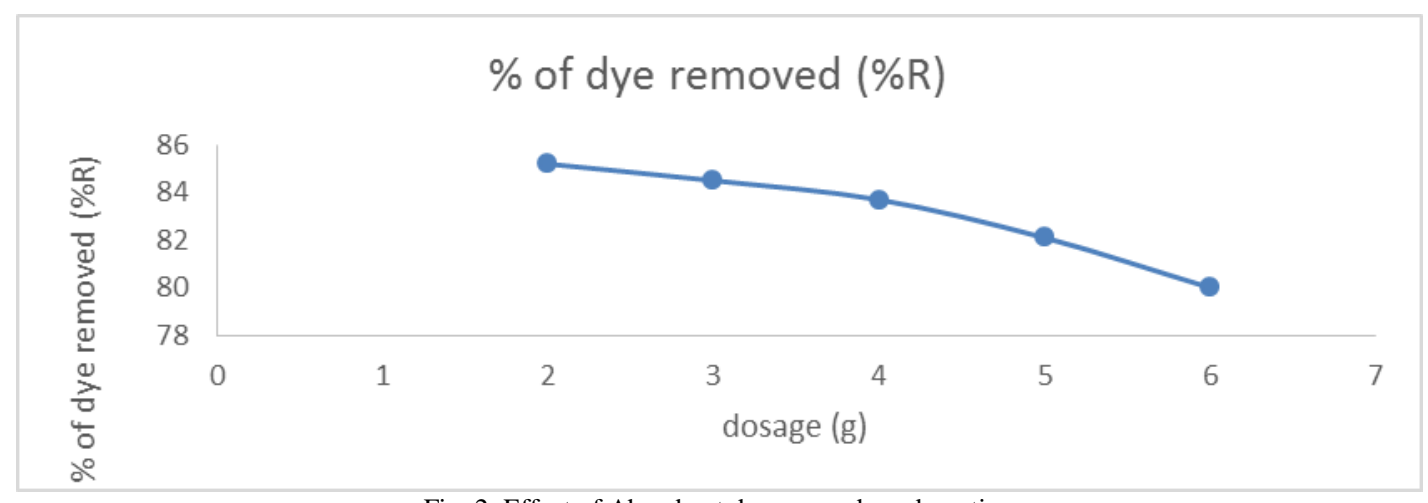

Fig. 2: Effect of Absorbent dosage on dye adsorption

Effect of Temperature on the Adsorption of Tartrazine Dye in Solution

The influence of dye adsorption on temperature was investigated within the range of $30^{\circ} \mathrm{C}$ to $70^{\circ} \mathrm{C}$. Theresults
Figure 3 indicate that the amount of dye adsorbed increased from 30 to $70^{\circ} \mathrm{C}$ respectively.

This observation is a line with a the reports made by other workers (Sumanjit, et al., 2007 Mishra et al.,2009,).

\section{$\%$ of dye absorbed (\%R)}

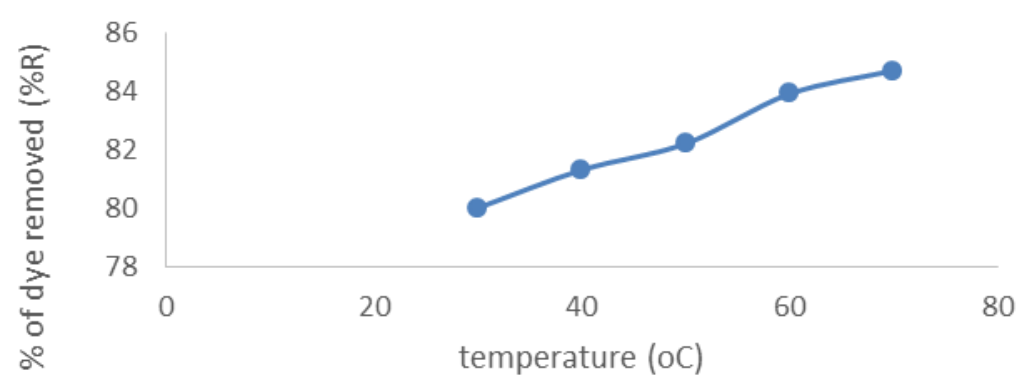

Fig. 3: effect of temperature on the adsorption of dye by groundnut shell adsorbent. 


\section{Effect of Dye Ion Concentration on Adsorption}

The result of this investigation shows the removal of dye with groundnut shell at various initial dye concentrations Figure 4 below. The adsorption capacity increased from $0.210 \mathrm{mg} / \mathrm{g}-1.213 \mathrm{mg} / \mathrm{g}$ with a maximum adsorption of $1.213 \mathrm{mg} / \mathrm{m}-50 \mathrm{mg} / \mathrm{L}$.

The percentage removal of the dye was observed to increase with the initial dye concentration (Figure 4). This behaviour could be attributed to the fact that as dye concentration is increasing, more dye is made available for adsorption on the adsorbent.

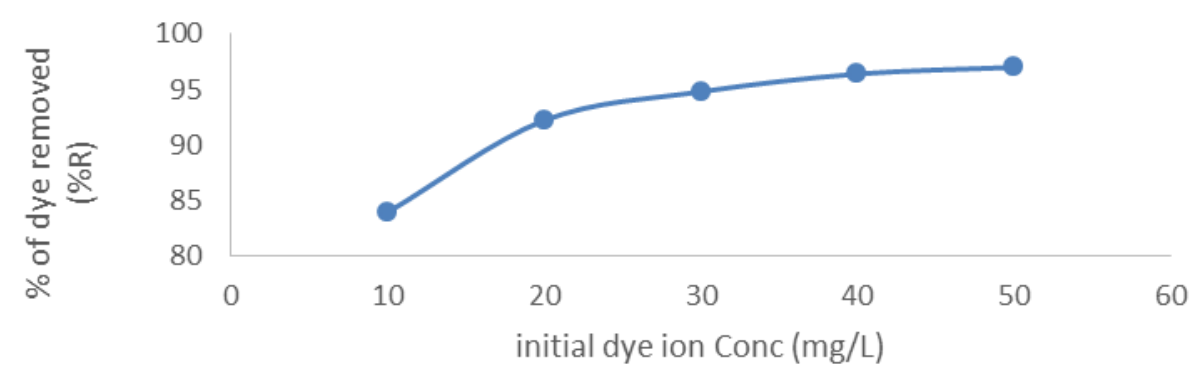

Fig. 4: Effect of TY dye ion concentration on the adsorption of dye by groundnut shell adsorbent

Effect of $\mathrm{pH}$ on the Adsorption of Tartrazine Dye in Solution

The $\mathrm{pH}$ of an aqueous system presents an important variable that may affect the uptake of the adsorbate. The chemical properties of both the adsorbate and the adsorbent vary with $\mathrm{pH}$. The $\mathrm{pH}$ dependence data for adsorption is represented in figure 5 below.
It was observed that when the $\mathrm{pH}$ of dye solution increased from 2.0 to 8.0 , the quantity of dye removed reduced from $0.219 \mathrm{mg} / \mathrm{g}$ to $0.204 \mathrm{mg} / \mathrm{g}$. Though at $\mathrm{pH} 10.0$, there was a rapid increase in the amount of dye adsorbed. This observation shows that the adsorption process was not favoured by increase in $\mathrm{pH}$ or alkalinity, hence $\mathrm{pH} 2$ was the optimum for the adsorbate removal.

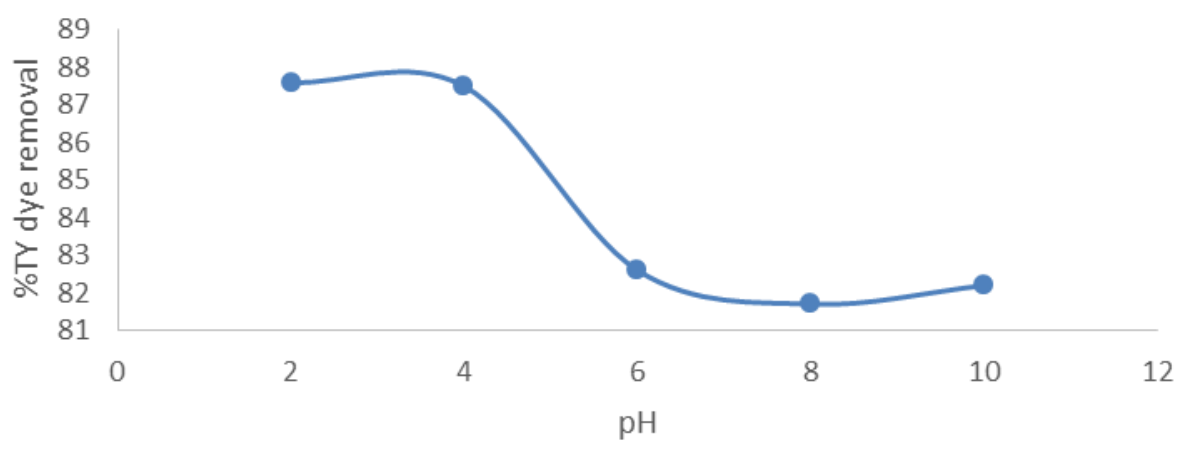

Fig. 5: Effect of $\mathrm{pH}$ on dye adsorption by groundnut shell adsorbent

\section{Langmuir Isotherm Evaluation of the Sorption Process}

The Langmuir isotherm model was used to estimate the maximum adsorption capacity corresponding to the complete monolayer coverage on the biomass surface. The linear flow between the specific adsorption (Ce/qe) against the equilibrium concentration $(\mathrm{Ce})$ are represented in Figure 6 and the linear isothermconstants; $\mathrm{q}_{\mathrm{m}} \mathrm{K}_{\mathrm{L}}$ and the coefficient of determinations are shown in Table 6 below
The $\mathrm{R}^{2}$ regression coefficient was 0.9988 . This suggests that the Langmuir Isotherm $\left(\mathrm{R}^{2}\right)$ obtained provides a good model of the adsorption process, by implication it is a monolayer surface adsorption process with favourable process since $\mathrm{K}_{\mathrm{L}}$ $(0.601)<1$

\begin{tabular}{|l|l|l|l|}
\hline Dye ion & $\mathrm{q}_{\mathrm{m}}\left(\mathrm{mg}^{-1}\right)$ & $\mathrm{K}_{\mathrm{L}}(\mathrm{Lg}-1)$ & $\mathrm{R}^{2}$ \\
\hline Tartrazine & 3.06 & 0.601 & 0.9988 \\
\hline
\end{tabular}




\section{langmuir plot}

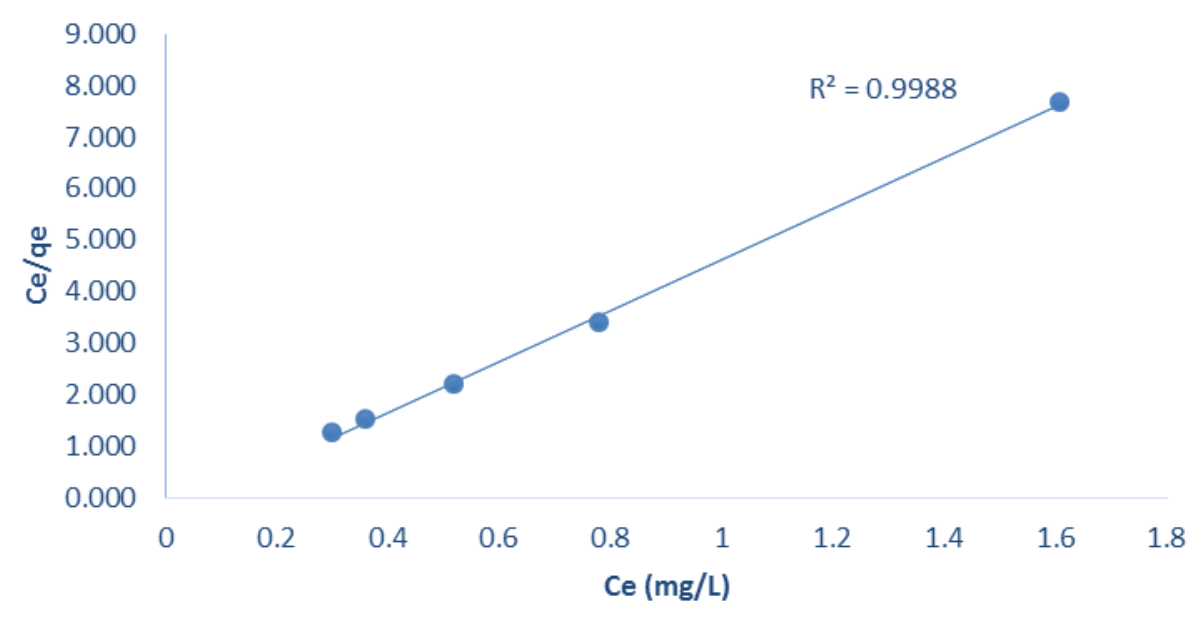

Fig. 6: Langmuir equilibrium

\section{Freundlich Isotherm}

The Freundlich model was employed to evaluate the adsorption intensity of the adsorbate on the adsorbent surface. The linear Freundlich model for the adsorption of the dye ion onto groundnut shell biomass are shown in Figure 7 below. Evaluation of the graph reveals that the Freundlich isotherm is also an appropriate model for the sorption process though less than that of Langmuir, this is evident in the $\mathrm{n}(0.969)$ that fell below 1 , hence heterogeneous adsorption was unfavourable. Table 7 shows the linear Freundlich sorption isotherm constant and the coefficient determination $\left(\mathrm{R}^{2}\right)$.

Considering the value of $\mathrm{R}^{2}$, the linear form of the Freundlich isotherm seems to produce a reasonable model for the sorption process under study.

Table 7: Freundlich equilibrium isotherm

\begin{tabular}{|c|c|c|c|}
\hline Dye & $\mathrm{I} / \mathrm{n}$ & $\mathrm{K}_{\mathrm{F}}$ & $\mathrm{R}^{2}$ \\
\hline Tartrazine yellow & 1.031 & 0.3495 & 0.9982 \\
\hline
\end{tabular}

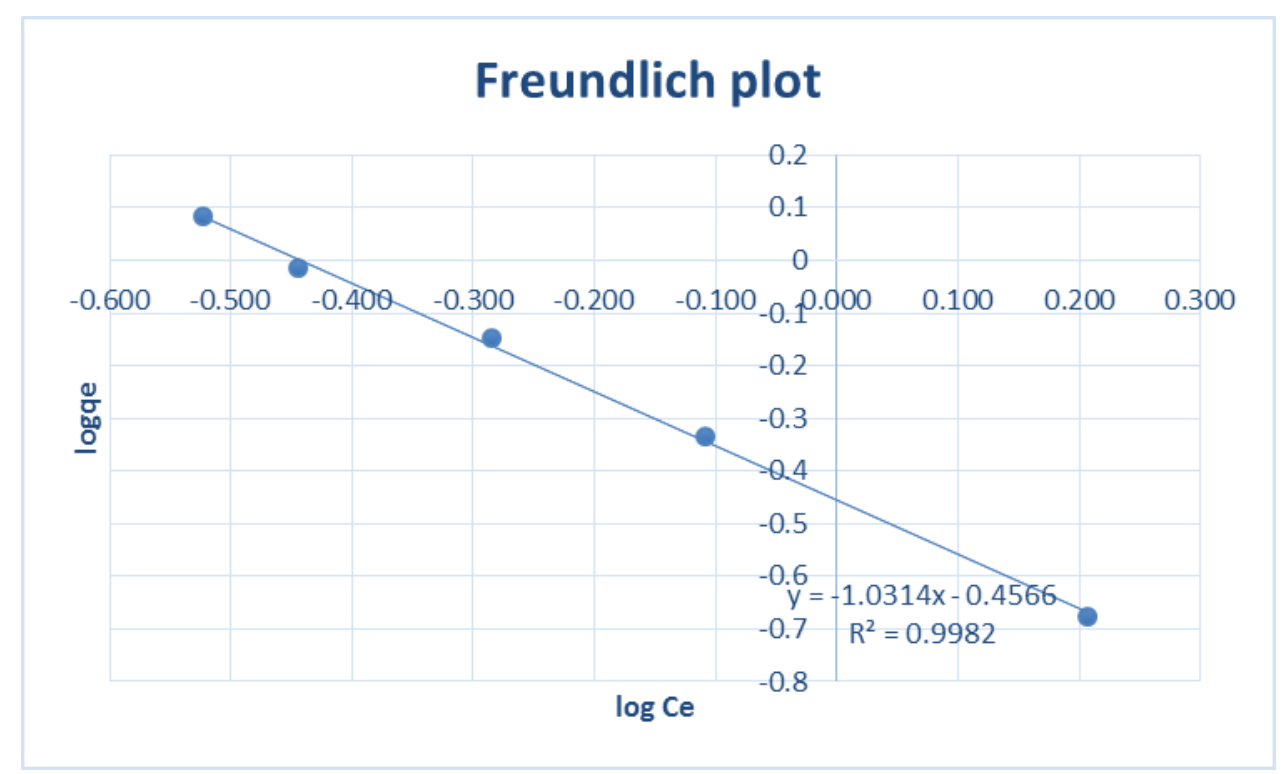

Fig. 7: Freundlich equilibrium isotherm model

\section{Adsorption Kinetics}

Kinetics of adsorption in one of the most important parameter employed in predicting the rate at which adsorption occur for a given system.
Pseudo-First Order Model

The plot of $\operatorname{In}(\mathrm{qe}-\mathrm{qt})$ against $\mathrm{t}$ as shown in Figure. 7 represents the pseudo-first order kinetics. From the graph it was observed that the relationship between the dye ion diffusivity, In(qe-qt) and time is linear which confirms that 
the model obeys a pseudo-first order model as shown in Table 7. The value of coefficient of determination $\mathrm{R}^{2}$ and other values indicates that Pseudo-first order model provides a good description for absorption of tartrazine yellow dye on groundnut shell biomass.

Table 8: Values of pseudo-first order kinetics parameters

\begin{tabular}{|l|l|l|l|}
\hline Dye ion & $\mathrm{K}_{1}$ & $\mathrm{q}_{\mathrm{e}}\left(\mathrm{mgg}^{-1}\right)$ & $\mathrm{R}^{2}$ \\
\hline Tartrazine yellow & 8.026 & 0.234 & 0.9072 \\
\hline
\end{tabular}

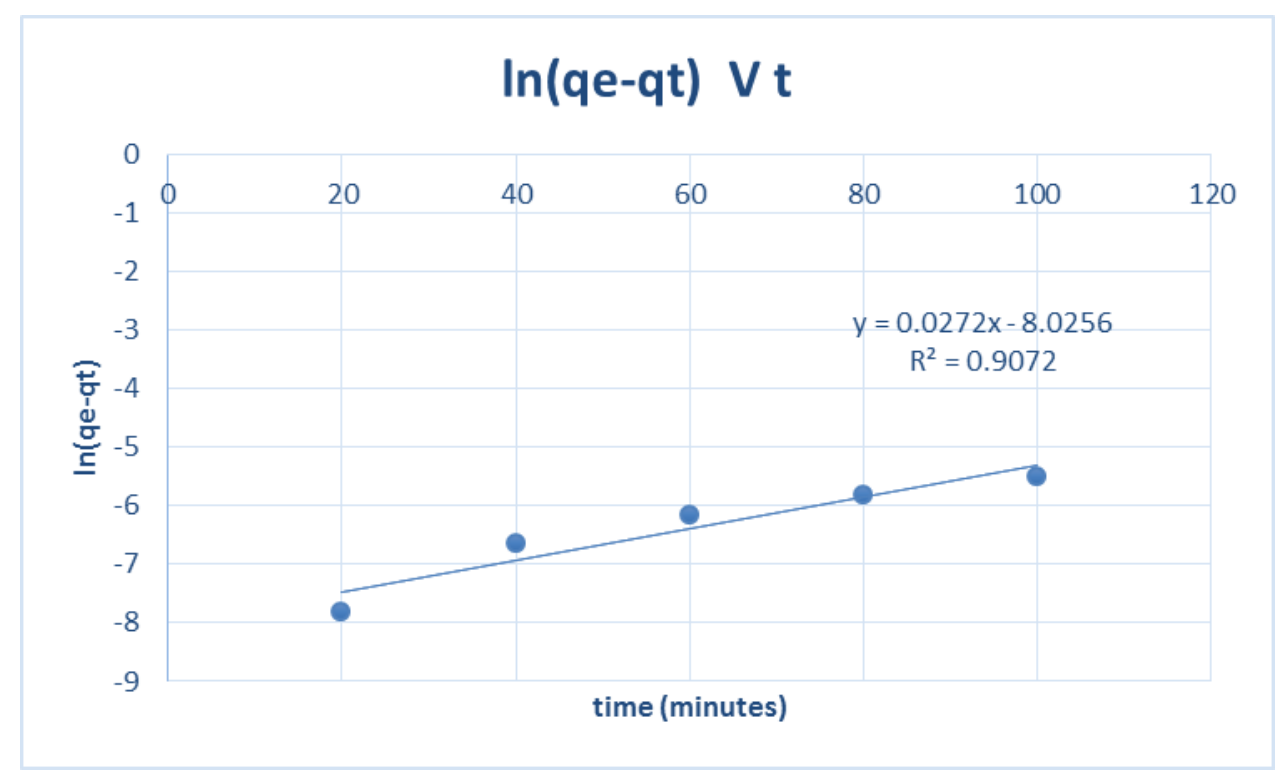

Fig. 8: Pseudo-first order plot

\section{Pseudo-Second Order Model}

The relationship between t/qt against $\mathrm{t}$ as indicated in Figure. 9 reveals the pseudo-second order kinetics. Arising from the plot, it is evident that the relationship between $\mathrm{t} / \mathrm{qt}$ and $\mathrm{t}$ is linear which confirms the model. However, the initial sorption rate ho, the equilibrium adsorption capacity qe, the pseudo-second order rate constant $\mathrm{K}_{2}$ and the coefficient of determination $\mathrm{R}^{2}$ are shown in Table 9. From the value of coefficient of determination $\mathrm{R}^{2}$, it is evident that pseudo-second order model provides a better interpretation for the adsorption process, better than the pseudo-first order model.

Table 9: Values of pseudo-second order kinetics parameters

\begin{tabular}{|l|l|l|l|l|l|}
\hline Dye ion & $\mathrm{K}_{2}$ & $\mathrm{q}_{\mathrm{e}}$ pred & $\mathrm{q}_{\mathrm{e}}$ exp & Ho & $\mathrm{R}^{2}$ \\
\hline Tartrazine yellow & -8.09 & 0.208 & 0.213 & -0.351 & 1 \\
\hline
\end{tabular}

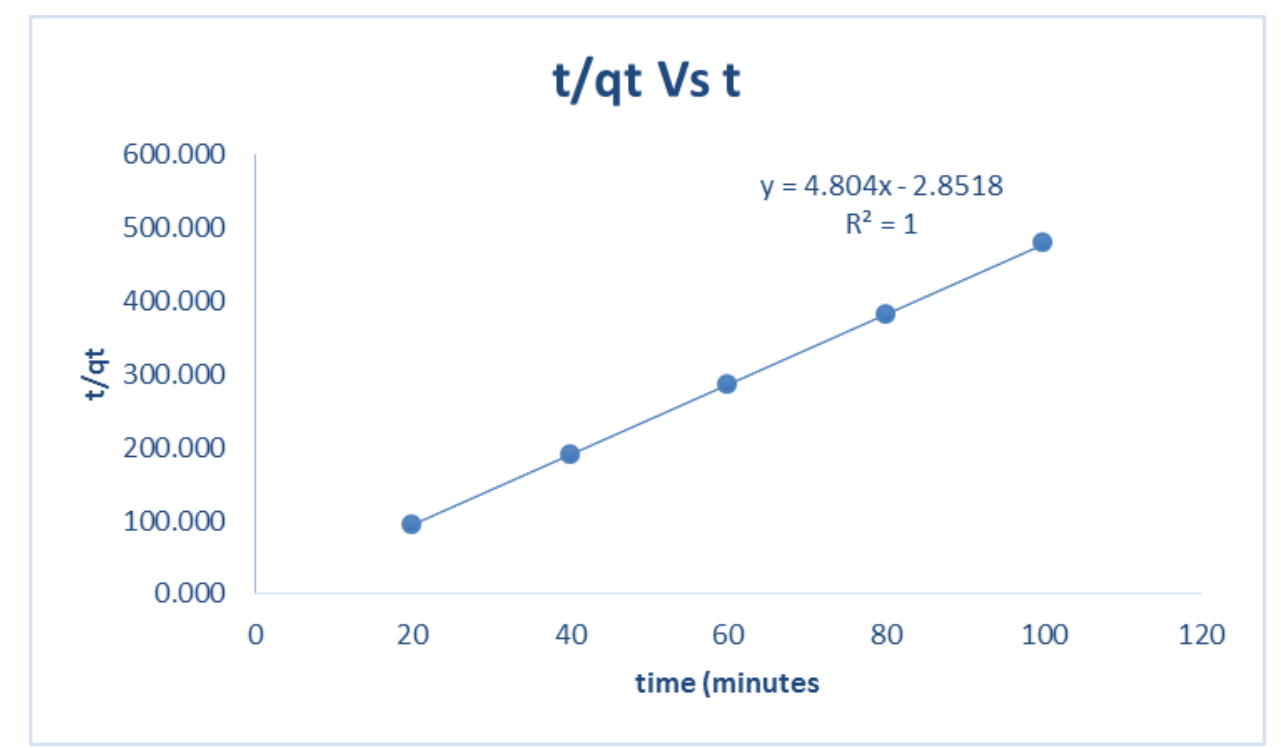

Fig. 9: Pseudo second order plot 


\section{Thermodynamic Parameters}

The values of thermodynamic parameters like entropy $\left(\Delta^{0} \mathrm{~S}\right)$, enthalpy $\left(\Delta^{0} \mathrm{H}\right)$ and free energy $\left(\Delta^{0} \mathrm{G}\right)$ of the adsorption process were deduced using the Langmuir constant $\mathrm{K}$ with the following equations.

$\begin{array}{ll}\Delta \mathrm{G} & =-R T \text { Ink } \\ \text { Ink }=\frac{\Delta S}{R}- & \frac{\Delta H}{R T}\end{array}$

$\Delta G=\Delta H-T \Delta S$

The value of the $\Delta \mathrm{H}^{0}$ and $\Delta \mathrm{S}^{0}$ were estimated from the slope and intercept of the linear variation of Ink with the reciprocal of temperature $(1 / \mathrm{T})$ as shown in Table 10 and in Figure

Table 10: Thermodynamic parameters of the adsorption process

\begin{tabular}{|c|c|c|c|c|}
\hline Temp. $\left({ }^{0} \mathrm{C}\right)$ & $\Delta \mathrm{H}^{0}(\mathrm{KJ} / \mathrm{mole})$ & $\Delta \mathrm{G}^{0}(\mathrm{KJ} / \mathrm{mole})$ & $\Delta \mathrm{S}^{0}(\mathrm{KJ})$ & $\mathrm{R}^{2}$ \\
\hline 30 & \multirow{5}{*}{7.172} & -3.473 & \multirow{5}{*}{0.00351} & \multirow{5}{*}{0.9867} \\
\hline 40 & & -3.824 & & \\
\hline 50 & & -4.175 & & \\
\hline 60 & & -4.526 & & \\
\hline 70 & & -4.878 & & \\
\hline
\end{tabular}

Arising from the Table above, the values of $\mathrm{R}^{2}(0.9867)$ vindicated the linearity fit of the data to Van't Hoff model also that of $\Delta \mathrm{G}^{0}$ at different temperatures are negative, which reflects that the adsorption process is so spontaneous and feasible. The value of enthalpy is also positive, which reveals the endothermic nature of the process. Meanwhile, the same observation has been reported in regards to the endothermic nature of the process by Hajira et al., (2008).

\section{thermodynamics plot}

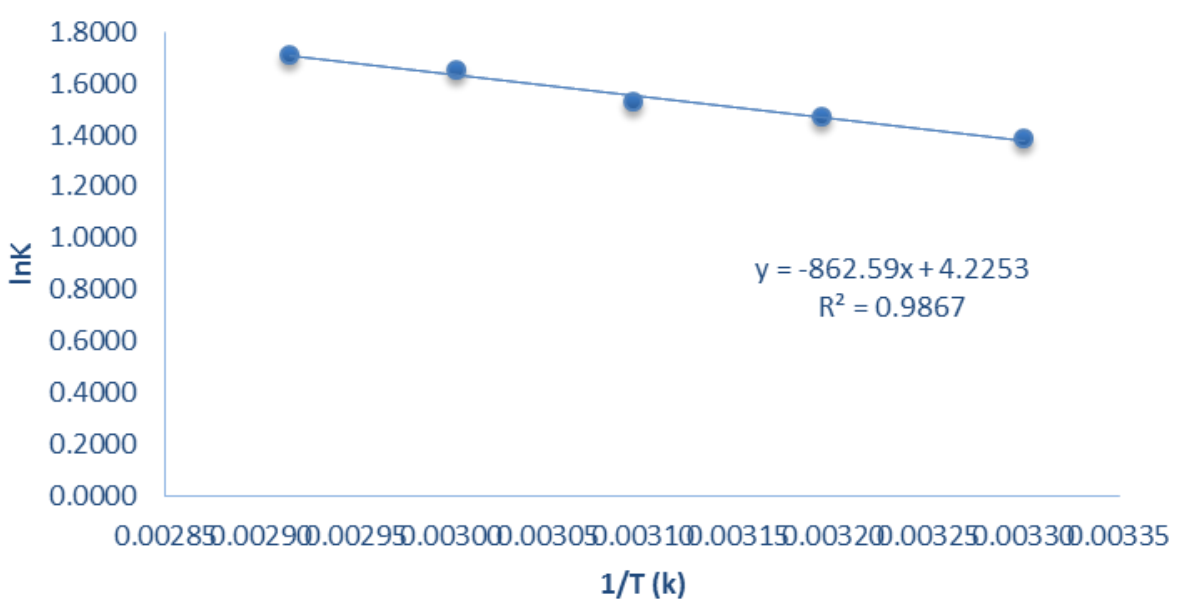

Fig. 10: Thermodynamic plot (plot of Ink against (1/T)

\section{CONCLUSION}

The potential of groundnut shell in the removal of tatrazine yellow dye from aqueous solution has been investigated. It was observed that increase in absorbent dosage decreased dye adsorption. However, the content of tatrazine dye adsorbed increased with increase in contact time. Similarly, increased in $\mathrm{pH}$, decreased the amount of dye removed from aqueous solution. The ability of the adsorbent in the removal of tatrazine yellow dye were well described by the Langmuir and Freundlich isotherm models. The process however, that fits the adsorption process is favoured by the pseudo-second order kinetics. The groundnut shell is thus a good adsorbent for the removal of tatrazine yellow from aqueous solution. This can be enlarged and adopted in industrial scale, hence the optimum conditions to operate this process have been determined.

\section{REFERENCES}

[1] Asiagwu, A.K., Omutu, P.E. and Alisa C.O. (2012). Journal of Chemical, Biological, and Physical Sciences vol. (3) : 4857.

[2] Asiagwu, A.K. (2013). Kinetic and thermodynamic model for the removal of ultramarine blue from aqueous solution using modified cassava peels. Nigerian journal of science and environment 12(1): 25-33

[3] Hajira T., Muhammed S. and Qazi J. (2008) "Removal of Basic Dye methylene Blue by using Bioabsorbent Ulva lactuca and sargassum". African Journal of Biotechnology. 7 (15). 2649-2655, 2010.

[4] Grag,V.K., Kumar, R and Gupta, R. (2004). Removal of malachite green dye from aqueous solution by adsorption using agro-industry waste; A case study of proscopis cineraria. Dye pigments 62: 1-10 
[5] Hameed, A.C Ahmed and K.N.A. Latiff, "Adsorption of basic dye (Methylene (blue) onto Activated Carbon preparedfrom rattan Sawdust". Dyes and Pigments Vol. 75, no. 1, pp.143149, 2011.

[6] HO, Y.S., Wase, D.A.J. and Foster C.F. (1996). "Kinetic Studies of Competitive Heavy metal Adsorption bySphagnum Moss peat". Environmental Technology,17:71-77.

[7] Mishra, S., Prakash D.J. and Ramakrishma G. (2010) "Characterization and utilization of Mahua Oil Cake-A New Adsorbent for Removal of Congo Red Dye from Aqueous phase", Electronic Journal of Environmental, Agricultural and Food Chemistry.

[8] Mohammed, M.M. (2004). Acid dye removal; comparision of surfactant modified FSM-16 with activated carbon derived from rice husk. Journal of colloid interface science 272: 22-34

[9] Sumanjit: Walia TPS and Ravneet K. (2012) "Removal of Health Hazards Causing Acidic Dyes from Aqueous Solutions by the Process of Adsorption" Online Journal of Health and Allied Sciences. 6(3) 1-10. 